\section{Healing after Partial Denudation of the Alveolar Process*}

by

EMmett R. COSTICH, ** D.D.S., PH.D. SIGURD P. RAMFJORD, *** L.D.S., PH.D.

Although extensive buccal and lingual denudation of the alveolar process has been abandoned, bone is often exposed at the alveolar crest and in interproximal areas during periodontal surgery. The purpose of the present investigation was to study the healing after surgical denudation of small areas of the alveolar process in humans.

\section{Material}

Ten immediate denture patients at The University of Michigan, School of Dentistry, participated in the study. The patients were in good health and varied from 26 to 57 years of age. Dental records, roentgenograms and clinical pictures of the patients were available. The periodontal health status varied from clinically normal gingiva to moderately advanced periodontitis. A block section of the experimental tooth with adjacent buccal soft tissues and alveolar process, at least to the middle of the root, was obtained from each patient at the time of insertion of the immediate denture.

\section{MeTHOD}

A standard record was kept providing detailed information about periodontal status and functional relations of the experimental teeth. A transverse horizontal notch extending into dentin was made on the labial surface of the experimental tooth, to serve as reference for clinical measurements before, during and after the surgery. ${ }^{1}$ The notch was made with a small diamond wheel, about $2 \mathrm{~mm}$ incisally to the free gingival margin. Measurements from the gingival margin of the notch to the free gingival margin, and to the bottom of the gingival sulcus or pocket were obtained with a blunted no. 2 silver point of the type used for root canal therapy. A cotton plier was used to grasp the point at the spot where the beaks of the plier fit into the reference notch. The measurements were made with a Boley gauge.

A labial and interproximal gingivectomy was then performed on the experimental tooth and the immediate

\footnotetext{
*The University of Michigan, School of Dentistry, Ann Arbor, Michigan 48104.

**University of Kentucky, College of Dentistry, Department of Oral Surgery, Lexington, Kentucky 40506.

***The University of Michigan, School of Dentistry, Department of Periodontics, Ann Arbor, Michigan 48104.
}

adjacent areas. The gingivectomy was done with a beveled incision which extended to the alveolar crest. Then the labial soft tissues, including the periosteum were removed over the experimental tooth leaving a strip of exposed bone 3 to $4 \mathrm{~mm}$ apically from the alveolar crest (Fig. 1), and approximately $6 \mathrm{~mm}$ wide mesiodistally.

Measurements from the reference notch to the remaining soft tissue attachment, to the alveolar crest and to the apical border of the bone exposure were recorded at the completion of the experimental surgery.

A surgical dressing (Wondr-Pak) was placed over the blood covered bone and soft tissue wound. The dressing was changed at weekly intervals until the wound healed. Some specimens were obtained before the healing was complete and in these cases the dressing was retained until the removal of the experimental block section.

Clinical pictures and measurements from the reference notch to the free gingival margin, and to the attachment level on the root surface were obtained just before removal of the specimens.

The surgical removal of block specimens was done according to a previously published method. ${ }^{1}$

The specimens were fixed in buffered formalin, decalcified and embedded in celluloidin. The entire blocks were sectioned in a serial manner and every fifth section was stained and studied. However, from the central area of the wound about twenty consecutive sections were stained.

A micrometer eye piece was used to measure from the slides the distances from the reference notch to the following: the gingival margin, the connective tissue attachment to cementum, and the alveolar crest.

\section{ReSUlTS}

\section{A. Clinical and Histometric Findings}

None of the patients experienced any severe pain or discomfort, although it took 3 to 4 weeks before the surgical lesion appeared to be healed.

All clinical and histometric measurements have been compiled in Table 1.

The presurgical measurements were obtained immediately prior to the anesthesia for the surgery. The measurements at the time of surgery were taken immediately after completion of the experimental surgery, and "level of surgery" refers to soft tissue attachment to the tooth at that time. Healing time indicates the time interval between the experimental surgery and the removal of the specimen. The clinical posthealing measurements were recorded immediately prior to the anesthesia for the surgical removal of the specimens. The listed micro- 
Table 1

Clinical and Histometric Measurements in Milimeters

\begin{tabular}{|c|c|c|c|c|c|c|c|c|c|c|c|c|c|c|c|c|c|c|}
\hline \multirow[b]{3}{*}{ 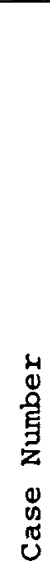 } & \multirow[b]{3}{*}{ 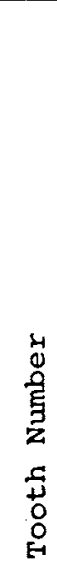 } & \multirow[b]{3}{*}{ 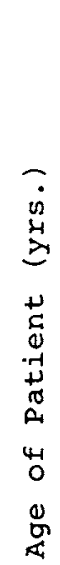 } & \multirow[b]{3}{*}{ 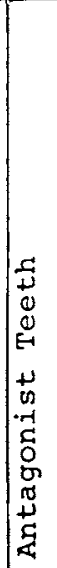 } & \multicolumn{2}{|c|}{$\begin{array}{l}\text { Pre- } \\
\text { surgical }\end{array}$} & \multicolumn{3}{|c|}{$\begin{array}{l}\text { Time of } \\
\text { Surgery }\end{array}$} & \multicolumn{6}{|c|}{ Post Healing } & \multicolumn{4}{|c|}{ Results } \\
\hline & & & & & & & & & & Clin & cal & Micr & Scok & & & & & \\
\hline & & & & 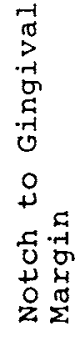 & 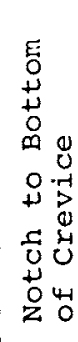 & 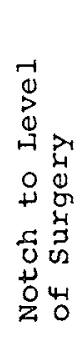 & 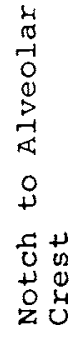 & 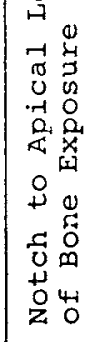 & 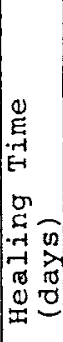 & 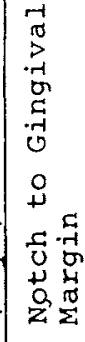 & 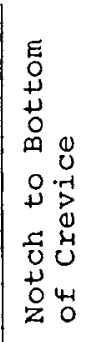 & 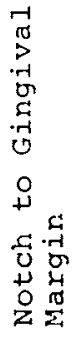 & 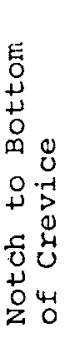 & 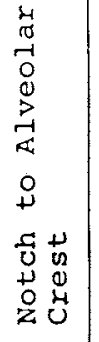 & 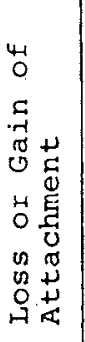 & 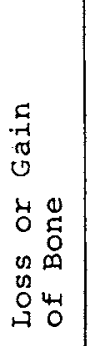 & 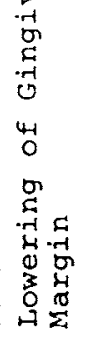 & 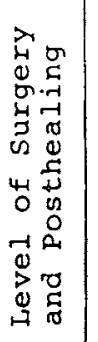 \\
\hline 1 & 8 & 33 & - & 2.0 & 3.9 & 4.3 & 6.0 & 9.0 & 7 & 5.6 & 5.7 & 4.9 & 4.9 & 5.7 & -1.0 & +0.3 & 3.6 & -0.6 \\
\hline 2 & 8 & 57 & 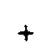 & 1.5 & 4.3 & 4.4 & 4.8 & 9.0 & 7 & 4.7 & 5.0 & 3.5 & 3.5 & 4.3 & $+n .8$ & +0.5 & 3.2 & +0.9 \\
\hline 3 & 7 & 35 & - & 1.2 & 3.4 & 3.2 & 6.2 & 9.5 & 14 & 4.0 & 4.0 & 4.2 & 5.6 & $>10.0$ & -2.2 & -3.8 & 2.8 & -2.2 \\
\hline 4 & 7 & 37 & 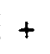 & 1.6 & 2.6 & 4.0 & 5.0 & 8.0 & 14 & 3.5 & 5.0 & 3.2 & 4.1 & 4.6 & -1.5 & +0.4 & 1.9 & 0.1 \\
\hline 5 & 8 & 28 & + & 1.5 & 3.2 & 4.8 & 5.5 & 8.5 & 22 & 4.1 & 4.2 & 3.9 & 5.0 & 6.2 & -1.8 & -0.7 & 2.6 & 0.2 \\
\hline 6 & 9 & 34 & 1 & 2.2 & 5.3 & 5.3 & 6.0 & 8.4 & 24 & 4.5 & 5.3 & 8 & 5.2 & 6.3 & +0.1 & -0.3 & 2.3 & +0.1 \\
\hline 7 & 10 & 51 & $\sigma^{\circ}$ & 2.2 & 4.5 & 5.0 & 6.0 & 9.5 & 25. & 4.8 & 4.9 & 4.2 & 4.9 & 5.9 & +0.4 & +0.1 & 2.6 & -0.1 \\
\hline 8 & $\theta^{\prime}$ & 26 & + & 2.2 & 3.7 & 4.3 & 4.5 & 8.7 & 41 & 3.5 & 4.3 & 3.0 & 3.5 & 8.0 & +0 & -3 & 1.3 & 0.8 \\
\hline 9 & 8 & 28 & + & 1.7 & 4.0 & 4.5 & 5.0 & 8.4 & 41 & 4.4 & 5.2 & 3.2 & 4.0 & 5.5 & 0.0 & -0.5 & 2.7 & +0.5 \\
\hline 10 & 10 & ות & . &. .3 & 3.4 & 3.7 & 4.6 & 7.0 & 43 & 3.7 & 4.2 & 3.5 & 4.0 & 7.3 & -0.6 & -2.7 & 2.4 & -0.3 \\
\hline
\end{tabular}

scopic measurements represent the average from three randomly selected tissue sections. Under Results are listed as loss $(-)$ or gain $(+)$ differences between the clinically obtained presurgical measurements between the notch and the bottom of the crevice and posthealing microscopic measurements between the notch and the connective tissue attachment level. This comparison of measurements is of limited significance since in most instances there had not been sufficient time for completion of the healing. Similarly, loss $(-)$ or gain $(+)$ of bone is based on comparison of the clinical measurements at the time of surgery and the microscopic measurements from the posthealing specmiens. In two instances (Case 3 and Case 8), no labial bone was present in the block sections indicating considerable loss of bone. The gingival margin did not regain its presurgical position. This is indicated in the next to the last column in Table 1, which represents the difference between the clinical posthealing and presurgical measurements.

There is very little difference between the measure- ments from the notch to the level of surgery at the time of surgery and the posthealing attachment level measured microscopically, indicating that the attachment level remained fairly well where it was placed at the time of surgery. (See last column, Table 1.)

\section{B. Histologic Findings}

The ten specimens represent essentially four time intervals of healing ( 1 week, 2 weeks, 3 weeks and 6 weeks, see Table 1). A composite description of the histologic findings will be given for each of these time intervals.

One Week After Experimental Surgery (Cases 1 and 2, Table 1). The labial bone is denuded for 3 to $4 \mathrm{~mm}$ apically to the alveolar crest (Fig. 2A). The surface of the bone is necrotic with empty lacunar spaces. The periodontal aspect of the alveolar bone is vital. Granulation tissue is protruding and starting to cover the dead bone from the periodontal membrane. Resorption and beginning sequestration is seen at the alveolar crest (Fig. 


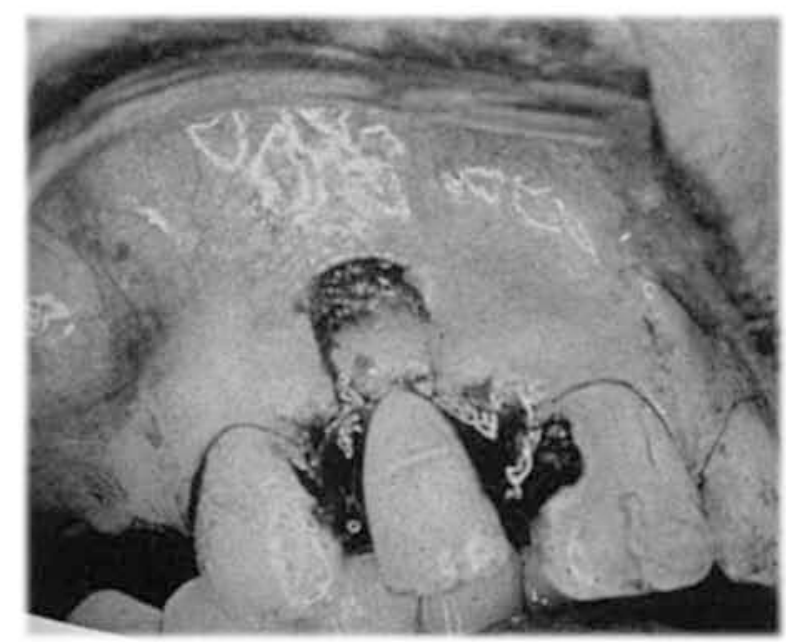

FIGURE 1. Clinical picture at completion of the experimental surgery.

2B). There is active bone resorption from the marrow spaces and fibrosis of the bone marrow with inflammation under the entire area of denudation. Bone resorption both from the labial surface and from the periodontal membrane side is seen toward the apical part of the specimen where the labial bone is covered by regenerating connective tissue and epithelium (Fig. 2C). The periosteum had apparently been separated from the bone inadvertently for some distance in this area during the

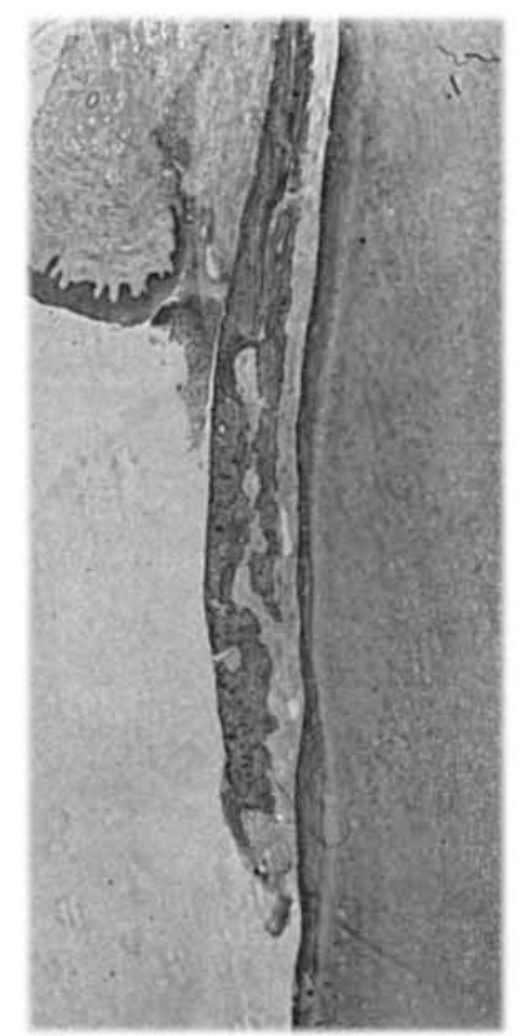

Figure 2A. Case 2. One week after surgery. Denudation of the alveolar process. Magnification X12. experimental surgery. There is acute inflammation at the surfaces of the soft tissue wounds and chronic inflammation extending superficially into the periodontal membrane at the coronal aspect.

Two Weeks After Experimental Surgery (Cases 3 and 4, Table 1). Almost the entire wound is covered by a thin layer of epithelium and highly inflamed granulation tissue (Fig. 3A). Sequestration and severe osteoclastie activity is involving all of the previously denuded and now mostly dead bone (Fig. 3B). The bone resorption is active from surface granulation tissue, from inflamed fibrotic marrow spaces and from the periodontal membrane. Subacute inflammation extends into the periodontal membrane.

Three to Three and One-Half Weeks After Experimental Surgery (Cases 5, 6, and 7, Table 1). One specimen shows resorption and sequestration of a residual part of the alveolar process (Fig. 4A), while the rest of the healing gingiva is covered by a thick layer of edematous, squamous mucosa. There are intermittent areas of osteoblastic and osteoclastic activity on the surface of the residual previously denuded bone (Fig. 4B). Some new bone has formed on the surface of necrotic bone which is being resorbed in other areas. Another specimen shows only a small spicule of residual alveolar process surrounded by severe inflammation (Fig. 4C).

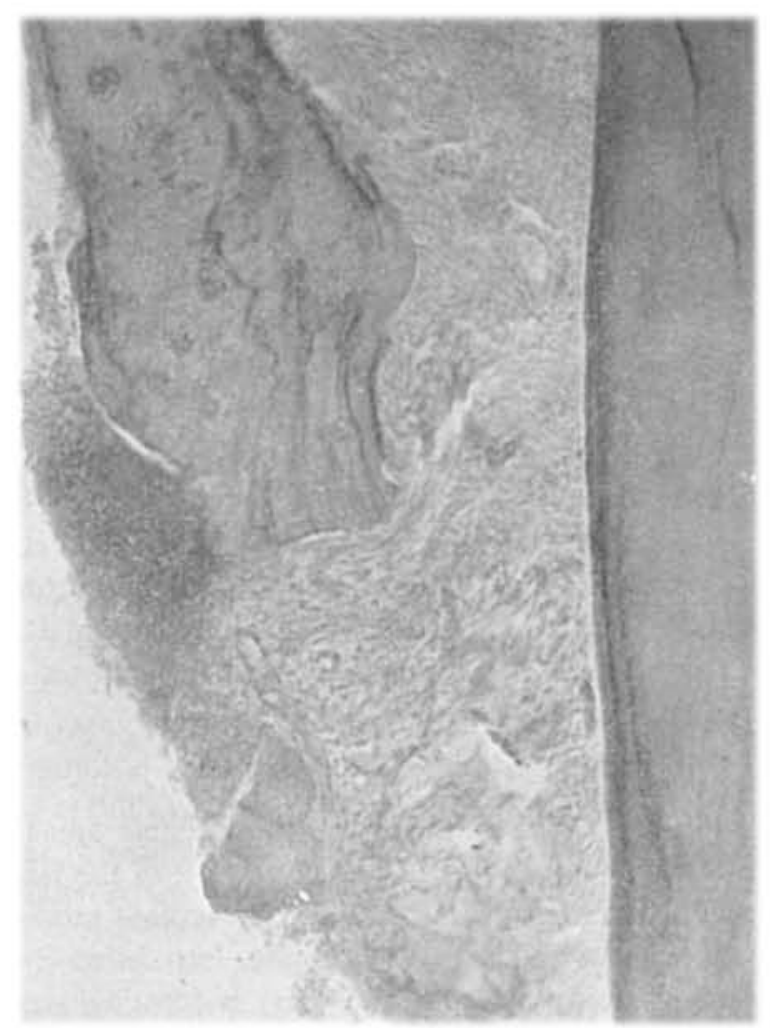

FIGURE 2B. High magnification of alveolar crest area from Fig. 2A. Granulation tissue extending from the periodontal membrane. Sequestrum on the surface. Magnification X106. 


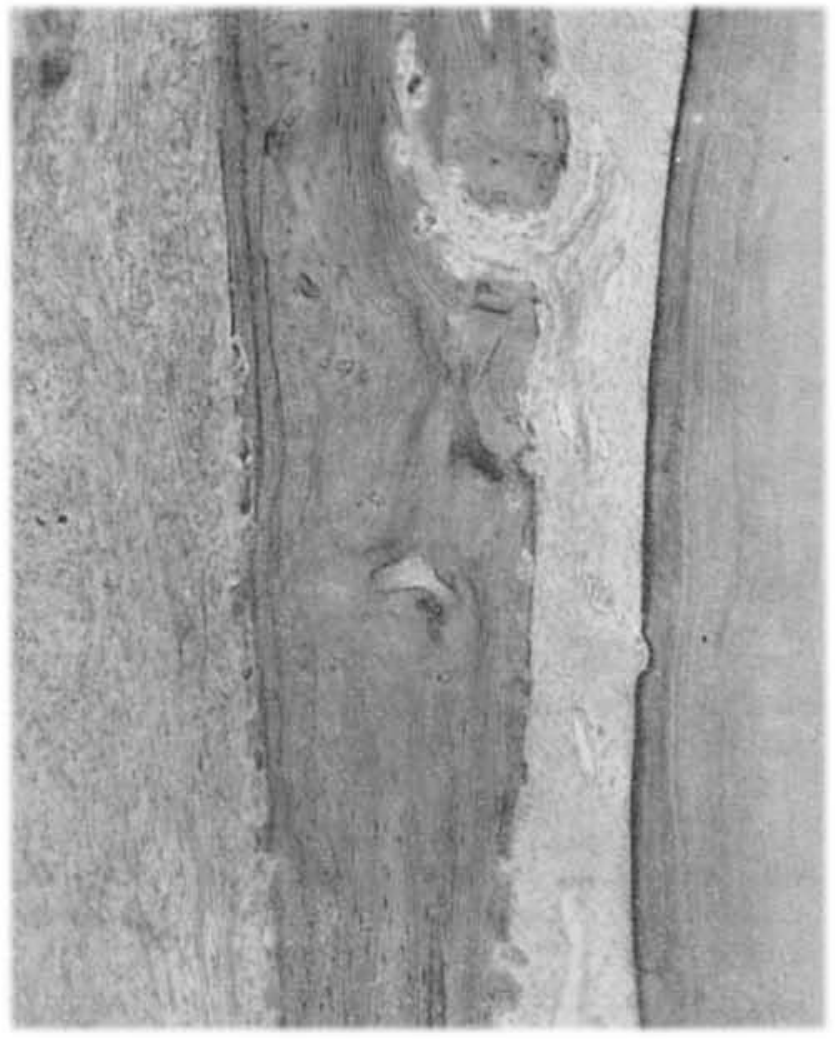

FIGURE 2C. High magnification from Fig. 2A. Connective tissue covering alveolar process at the apical border of denudation. Bone resorption both from the labial and periodontal membrane side. Magnification X86.

There are numerous resorption lacunae with evidence of beginning repair on the root surface of one tooth (Fig. 4D), and new bone formation is initiating the rebuilding of lost alveolar process in that specimen. Another specimen shows some residual vital bone on the periodontal membrane side of the previously denuded bone.

The gingivae of all specimens are covered by squamous epithelium with beginning parakeratosis, and there is evidence of early development of a shallow gingival crevice and epithelial attachment (Fig. 4E). The connective tissue is vascular and made up mainly of young fibroblasts. There is severe chronic inflammation. Bacterial plaque and calculus have started to form on the roots of the teeth.

Six Weeks After Experimental Surgery (Cases 8, 9, and 10, Table 1). There are still microscopic areas of sequestration (Figs. 5A and 5B), but most of the labial bone wall that was denuded surgically is now missing. The gingiva has regenerated partially, but shows focal areas of chronic inflammation. Bone is forming at the new alceolar crest (Fig. 5C). Microscopic areas of root resorption are undergoing repair (Fig. 5D). Small amounts of plaque and calculus are present on the three teeth. The new gingival crevices were shallow, but gin-

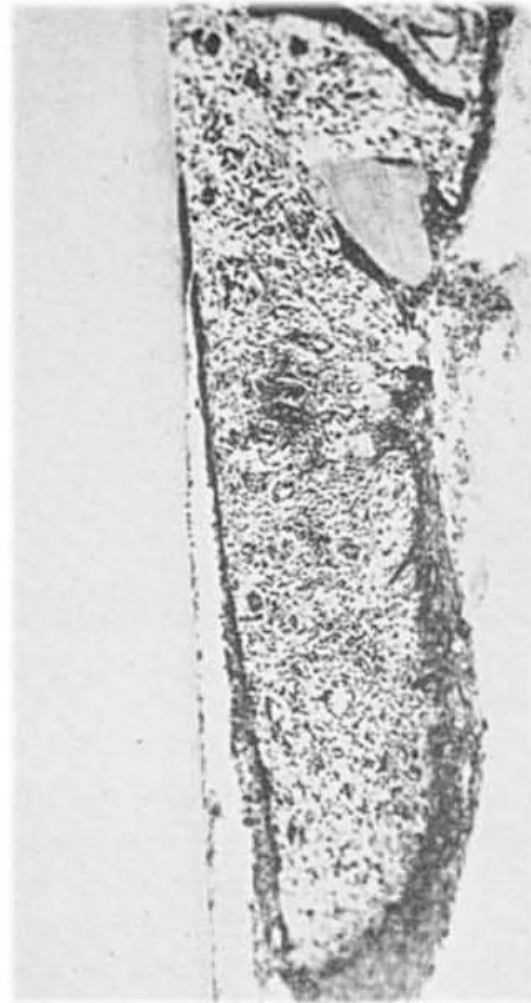

Figure 3A. Case 3. Two weeks after surgery. Granulation tissue covered by a thin layer of epithelium. One sequestrum close to surface. Magnification $X 141$.

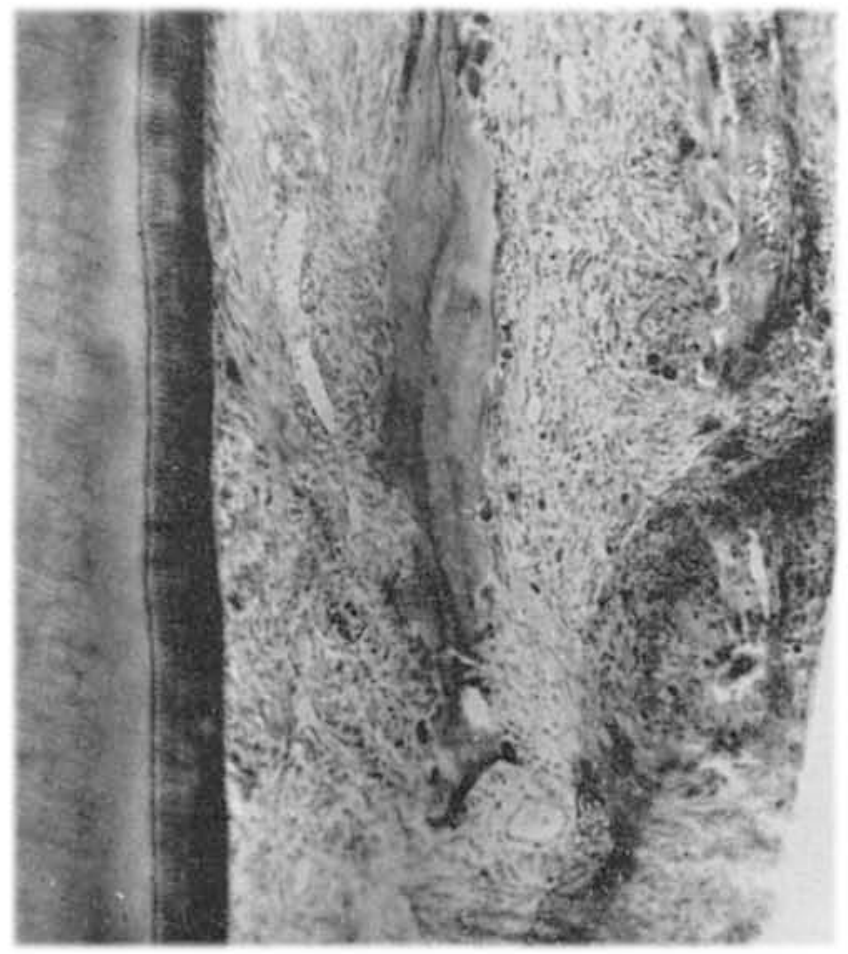

FIGURE 3B. Case 4. Two and a half weeks after surgery. Osteoclastic activity from granulation tissue over previously denuded bone. Magnification X86. 


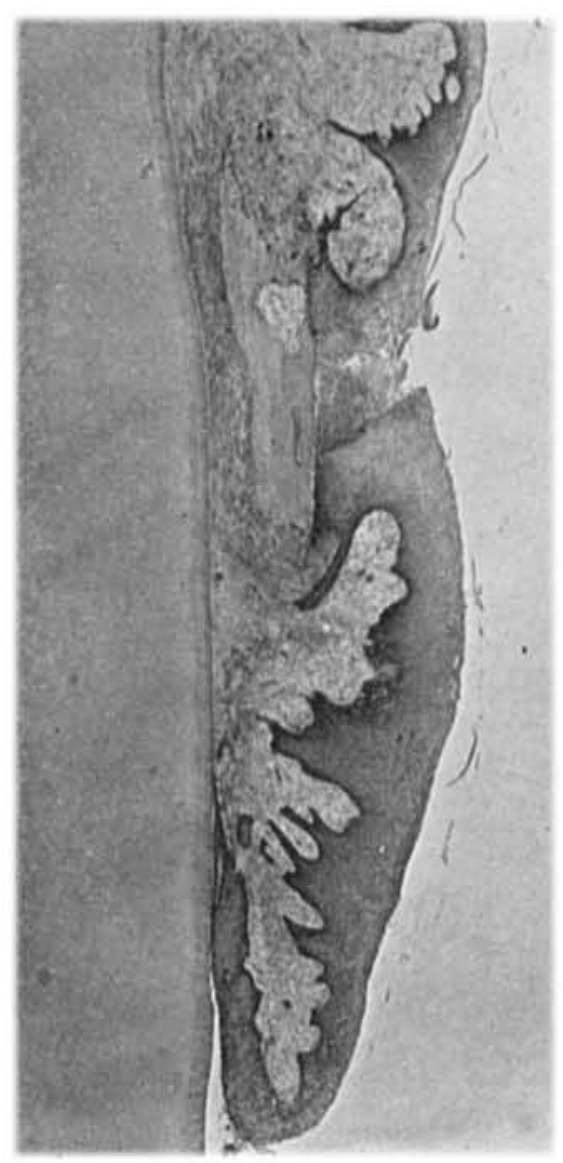

Figure 4A. Case 5. Three weeks after surgery. Resorption and sequestration of alveolar process. Severe chronic inflammation. Magnification X26.

gival inflammation extended to the bottom of the epithelial attachment in two of the three specimens, indicating that a physiologic epithelial seal is present in only one of the specimens.

\section{Discussion}

Since the classical research of Wilderman, Wentz and $\mathrm{Orban}^{2}$ stemmed the tide of "bone denudation to gain attached gingiva," there have been only a few histologic investigations of surgical denudation of the alveolar process. ${ }^{3-5}$ The only study in humans is by Pfeifer $^{5}$ who studied healing following apically repositioned flaps with 2 to $3 \mathrm{~mm}$ of exposed bone. His study extended over only a 21-day period and showed minimal loss of bone following denudation.

The present study showed a much more severe and longer lasting bone reaction than Pfeifer $^{5}$ described.

Sequestration and bone resorption was present 6 weeks after the surgery, and repair was not by any means complete at that time.

The most surprising finding not described previously

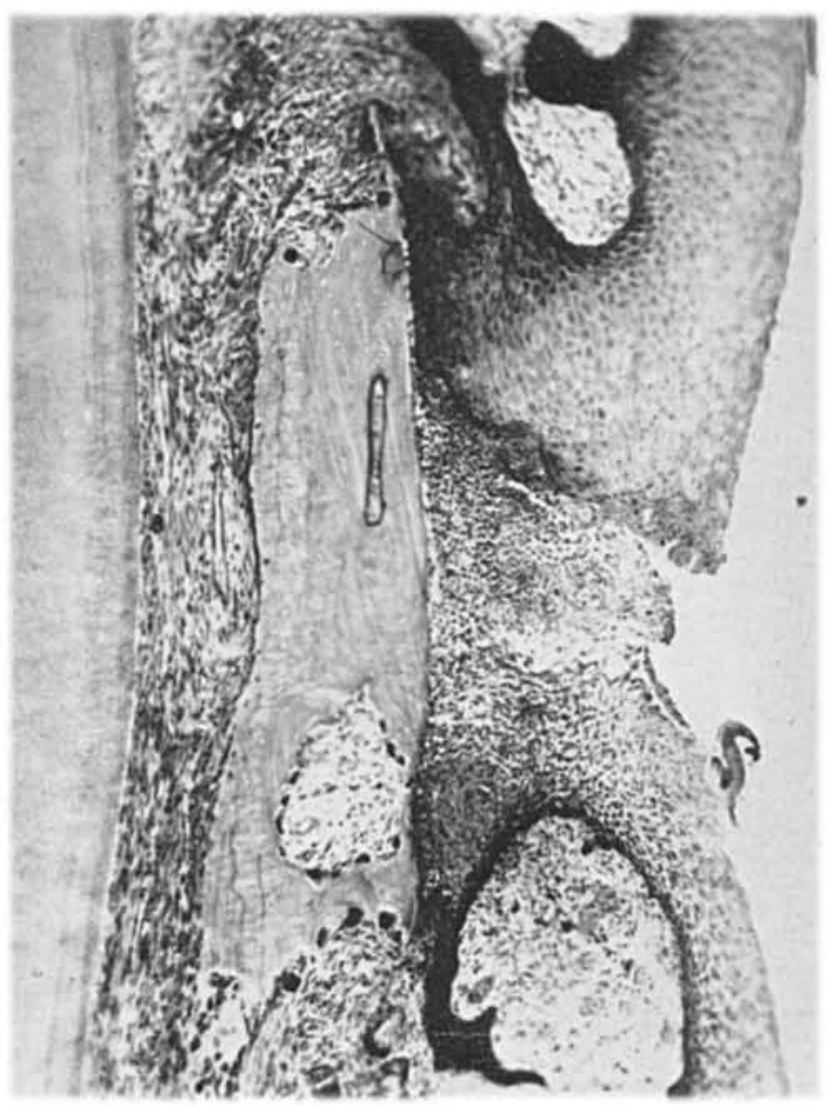

Figure 4B. High magnification from Fig. 4A. Necrotic bone with osteoclasts, but also some new bone formation on the periodontal membrane side. Magnification X86.

following this type of surgery was resorption of cementum which was seen in three of the ten cases. However, the cemental resorption was undergoing repair in the 6-weeks specimens and this may have ended in complete repair if left undisturbed.

The disparity was also striking between the clinical evidence of gingival healing and the histologic evidence of simultaneous inflammation in the deeper periodontal tissues with progressive bone resorption.

Granulation tissue and epithelium readily proliferate over the exposed dead bone surface and give clinical evidence of complete healing while severe inflammatory reactions gradually extend to the cementum. Bone regeneration may take place on the surface of necrotic bone; but eventually the dead bone will be resorbed and this resorption may go on for at least 6 weeks after a relatively small denudation of the alveolar process.

Besides the previously described ${ }^{2-5}$ bone resorption from the marrow spaces and the periodontal membrane, there was ample evidence of bone resorption from the new granulation and connective tissue which in a short time covered the dead bone. As indicated by previous investigators, the pattern of bone resorption was influ- 


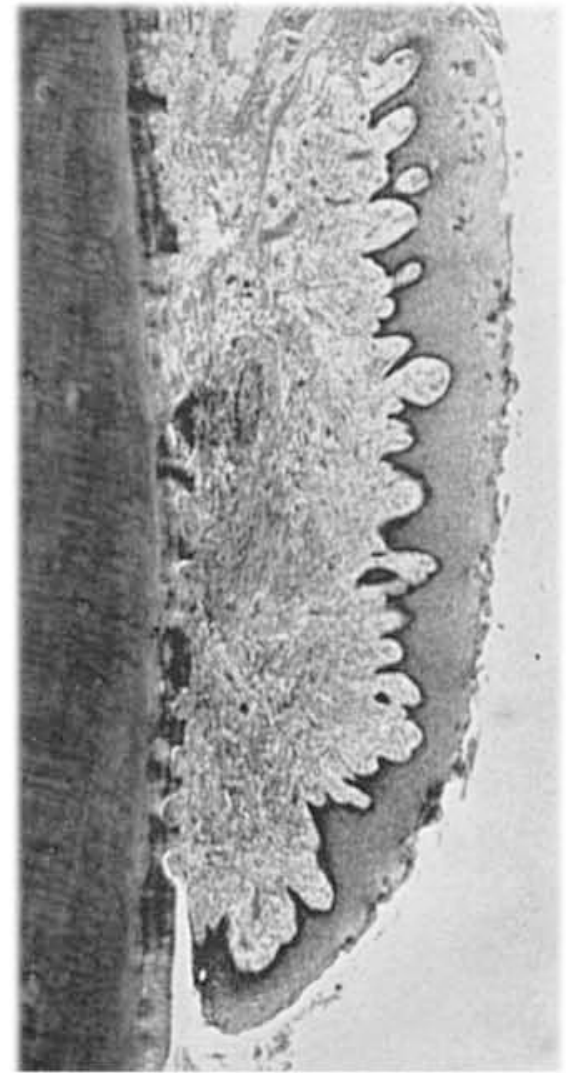

Figure 4C. Case 6. Three and a half weeks after surgery. Small sequestrum in central area of specimen. The rest of the labial bone has been resorbed. Resorption lacunae in cementum. Magnification X35.

enced by the thickness and structure of the labial bone. In cases of a thick labial bone plate with marrow spaces, the necrosis and bone resorption was initially confined to the outer part of the alveolar process. With a thin cortical labial bone plate, the resorption started from the alveolar crest, from perforations through the bone including Haversian canals from the periodontal membrane side, and from covering granulation tissue. However, it appeared from the longer term specimens ( 3 and 6 weeks) that the postsurgical inflammation had a tendency to extend into the periodontal membrane and lead to a delayed resorption of the alveolar bone even in the cases with obvious marrow space separation between the alveolar process and the alveolar bone.

The well-defined phases of osteoclasis, osteoblastic activity and functional repair described by previous investigators ${ }^{2,5}$ were not confirmed in the present study. We found a much greater overlap of osteoclastic and osteoblastic activity and a more severe and prolonged deep periodontal inflammation than previous investigators have described. It appears that denudation even of small parts of the alveolar process disturbs tissue metabolism severely and may lead to profound and pro-

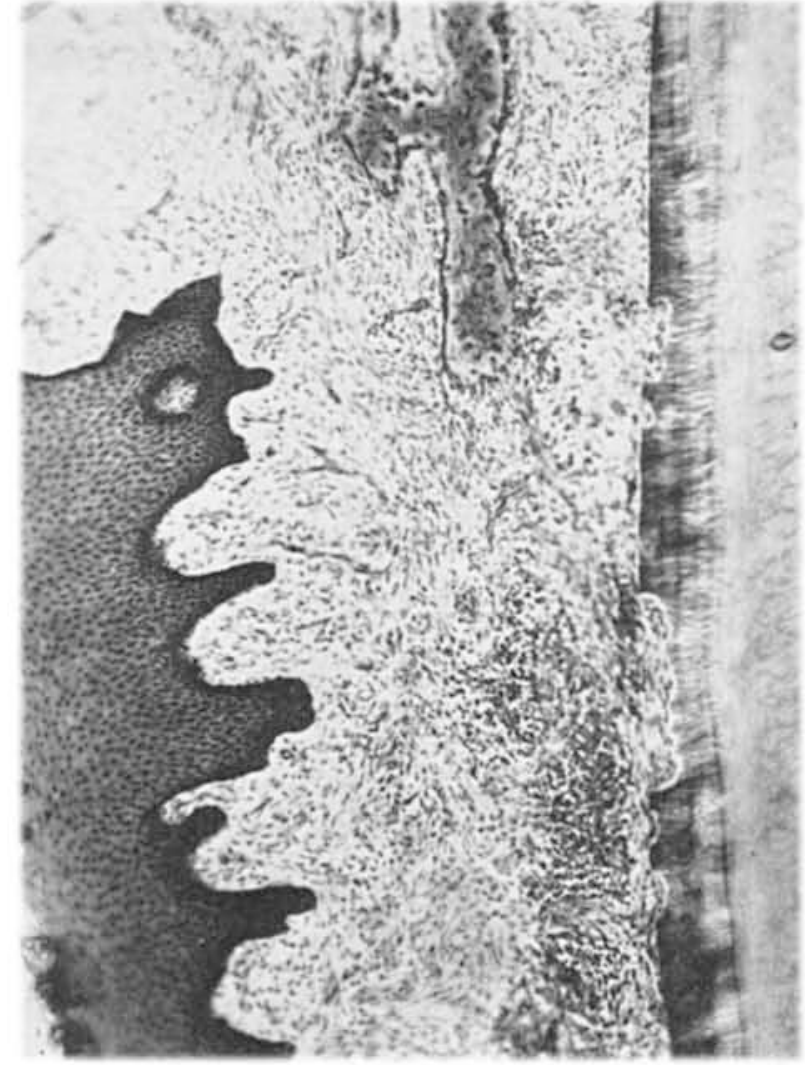

FIGURE 4D. High magnification from same specimen as $4 C$. Beginning repair of cementum and alveolar process. Chronic inflammation. Magnification X86.

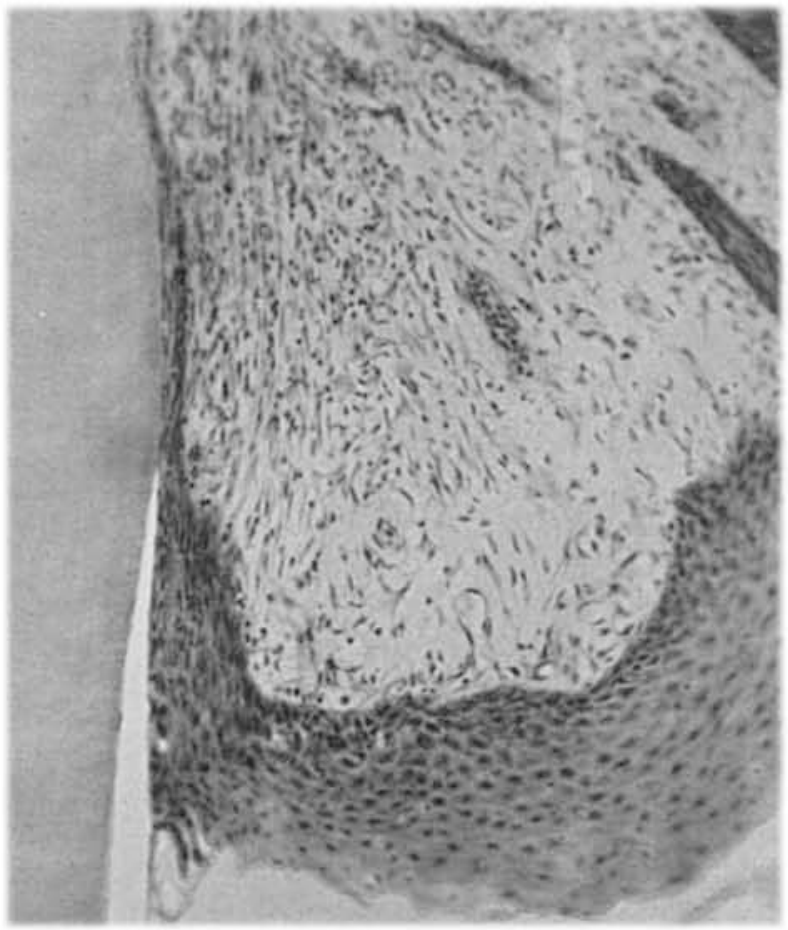

FIgURE 4E. Case 7. Three and a half weeks after surgery. Development of a new shallow gingival crevice and epithelial attachment. Magnification X86. 


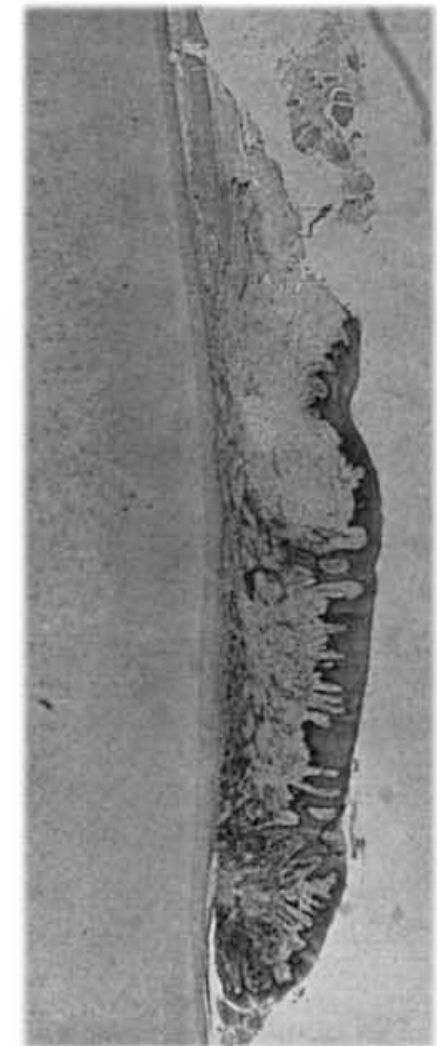

Figure 5A. Case 10. Six weeks after surgery. Focal areas of small sequestra and severe chronic inflammation in the regenerated gingiva. Large part of labial bone wall is missing. Magnification $X 15$.

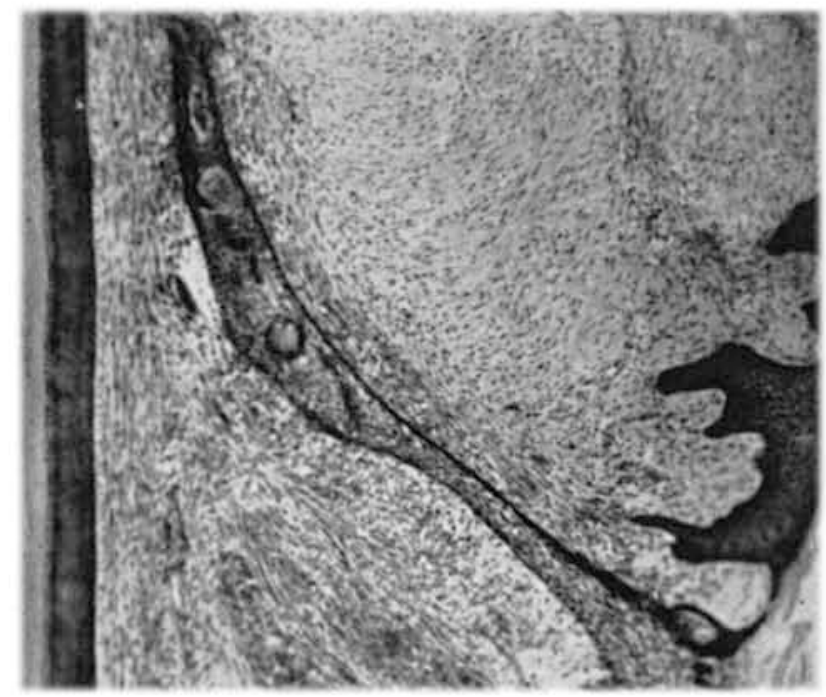

Figure 5B. Case 8. Six weeks after surgery. Sequestration of residual spiculae of labial bone. Magnification X90.

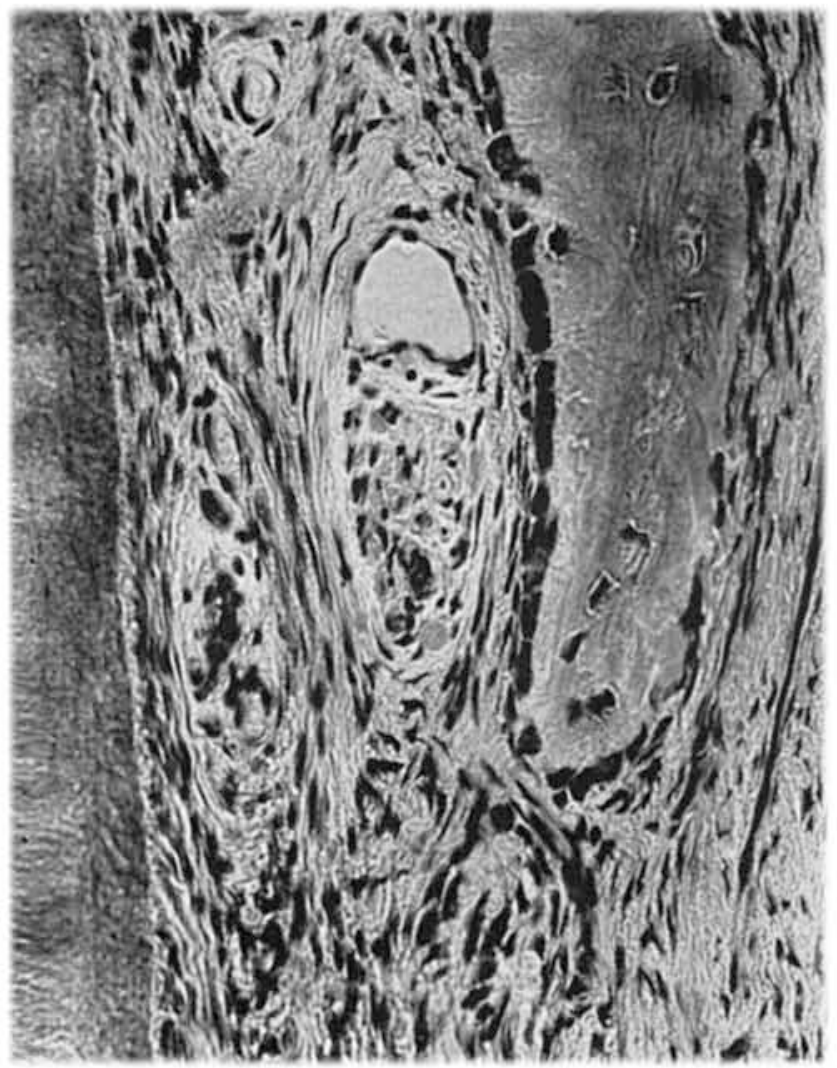

Figure 5C. Same specimen as Fig. 5A. Regeneration of alveolar crest. Magnification X317.

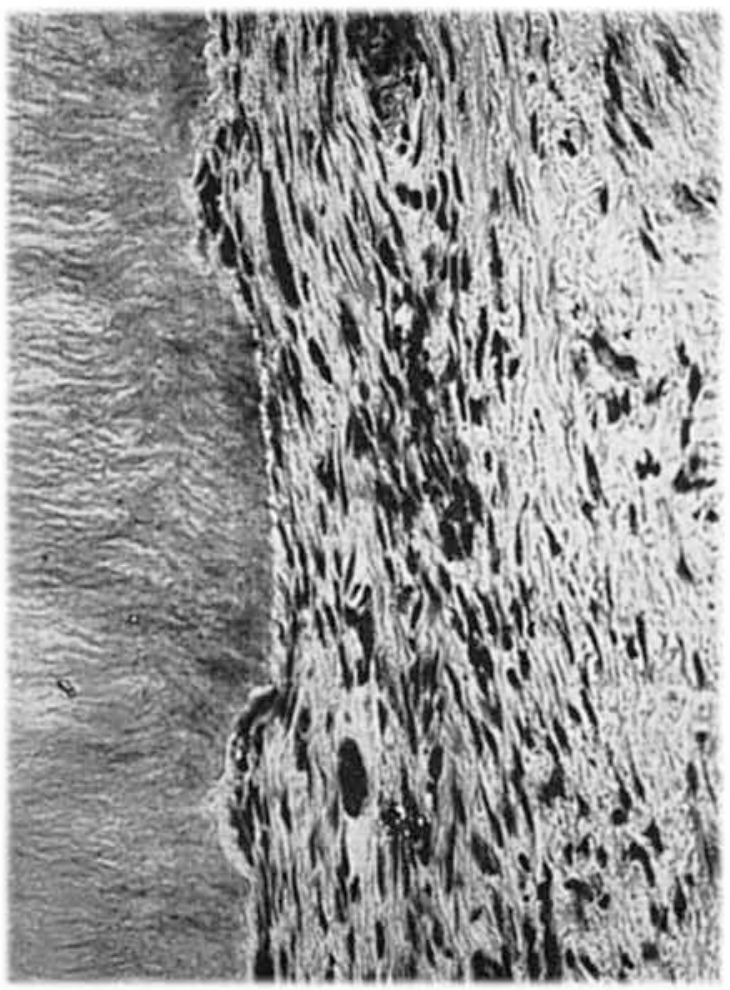

FIgURE 5D. Same specimen as Fig. 5A. Repair of resorption lacunae in cementum. Magnification X317. 
longed destructive tissue reactions, which obviously should be avoided whenever possible.

The extent of repair and regeneration following bone denudation in humans can not be assessed from the present study since repair still was active when the last specimens were obtained 6 weeks after the experimental surgery.

It is interesting to note that the bottom of the new epithelial attachment became located very closely to the level of the surgery in nine of ten cases (see Table 1). Similar observations have been made following other types of periodontal surgery, ${ }^{1}$ but a longer time of postsurgical observation may possibly alter this initial location of the junction between the epithelial and the connective tissue attachment. Although the new gingival crevice was shallow in all instances a physiologically functioning epithelial attachment without associated inflammation at the epithelium-connective tissue junction was seen only in one of the 6-weeks specimens.

\section{SUMMARY}

The clinical and histologic sequellae to denudation of a small area of alveolar process over one anterior tooth have been studied in ten patients. Each provided a postsurgical block specimen of the experimental tooth and the surrounding tissues.

Severe inflammation spread into the periodontal membrane both from the crestal opening following the surgery and through the denuded and partially necrotic bone. The periodontal reaction to the experimental surgery was much more severe and prolonged than described by previous investigators, and included in three instances cemental resorption.

The healing was not completed within the 6-weeks period of the present investigation.

Loss of bone seemed at least temporarily to be a more serious sequellae than loss of attachment following this type of surgery.

\section{Conclusions}

1. Avoid as much as possible leaving bone denuded after periodontal surgery.

2. Both inflammation and healing following bone denudation continue in the deeper periodontal tissues for several weeks after the healing clinically appears to be complete.

\section{REFERENCES}

1. Ramfjord, S. P. and Costich, E. R.: Healing after simple gingivectomy. J. Periodont., 34:401, 1963.

2. Wilderman, M. N., Wentz, F. M. and Orban, B. J.: Histogenesis of repair after mucogingival surgery. J. Periodont., 31:283, 1960.

3. Chacker, F. M. and Cohen, D. W.: Regeneration of gingival tissues in non-human primates. J. Dent. Res., 39: $743,1960$.

4. Glickman, I., Smulow, J., O'Brien, T. and Tanner, R.: Healing of the periodontium following mucogingival surgery. Oral Surg., Oral Med., and Oral Path., 16:530, 1963.

5. Pfeifer, J. S.: The growth of gingival tissues over denuded bone. J. Periodont., 34:10, 1963.

\section{Abstracts}

White Sponge Nevus in the Oral Regions

Gardner, A. F

J. Pros. Dent. 18:39-45, July 1967

A review of the literature revealed 28 previously reported cases of white sponge nevus of the oral mucosa, which showed various clinical appearances. The reported lesions showed familial incidences and the histopathology revealed hyperplasia, acanthosis dyskeratosis, fusion and elongation of rete pegs, intact basement membrane, and no inflammation. Two unrelated patients that were reported in this article and the 28 reported in the literature were identical histopathologically although different clinical criteria was represented. Division of Drug Surveillance, Bureau of Medicine, Food and Drug Administration, Department of Health, Education, and Welfare, Washington, D.C.
The Effect of Crown Margnal Depth UPON GINGIVAL TISSUE

Marcum, J. S.

J. Pros. Dent. 17:479-487, May 1967

A total of 600 histological slides were made of 66 gold crowns that were finished above and below and even with the gingival crests in six dogs that were sacrificed at time intervals of 1,2 , and 3 months. Crowns that were even with the gingival crest caused the least inflammatory response, while the crowns with margins above or below the crest caused the most severe inflammatory process no matter how long the restoration was left in place. Evaluation of the patient relative to periodontal health, caries susceptibility and other factors is significant in the selection of crown marginal depth. University of Louisville, School of Dentistry, Louisville, Kentucky. 